Brit. J. prev. soc. Med. (1975), 29, 135-146

\title{
The interplay of changes in society, reproductive habits, and obstetric practice in Scotland between 1922 and 1972*
}

\author{
SIR DUGALD BAIRD \\ Emeritus Professor of Obstetrics and Gynaecology, Aberdeen University
}

The last half century has seen great improvements in the standard of living of the British people and in their level of health and physique. This has been accompanied by changes in attitudes to sex, reproduction, family size, and the status of women in society. At the same time the standard of obstetric care available has improved greatly as a result of the National Health Service and advances in knowledge brought about by research.

In the early days of the present century social conditions were still very bad in Britain, as demonstrated by the very poor physique and health of young men conscripted to the armed forces in 1917. Conditions deteriorated still further because of the crippling cost of the war, social unrest, and finally the worldwide depression between 1926 and 1934 .

At that time most births took place at home with a 'handywoman' in attendance. She called a general practitioner to deliver the baby if and when she judged this to be necessary. The teaching of obstetrics to medical students was inadequate and there was no postgraduate training, so that family doctors had to acquire the necessary special skill by trial and error.

The mother was at risk of serious injury to her health and even of death. In the early 1930s over 400 mothers died in childbirth each year in Scotland. The maternal mortality rate did not begin to fall until 1936 after the discovery of 'prontosil rubrum' which was effective against the haemolytic streptococcus, the most important cause of maternal mortality at this time. The second world war was largely responsible for the rapid development of blood transfusion services which prevented many

*The Maurice Bloch Lecture given at the University of Glasgow, 25 October 1974. deaths from haemorrhage. Better antenatal care reduced the death rate from hypertensive complications of pregnancy and improved methods of anaesthesia made obstetric operations safer. The Maternity Services Scotland Act (1937) enabled the local health authorities to develop domiciliary maternity services, staffed by trained midwives and general practitioners who were experienced in clinical obstetrics. It became illegal for 'untrained' women to attend mothers in childbirth for financial gain. There was, however, a great scarcity of hospital beds for the treatment of high-risk and emergency cases.

By 1971 , more than $95 \%$ of all births in Scotland were taking place in hospital, and in that year the number of maternal deaths was 17 compared with over 400 annually before 1936 . The findings of an inquiry into 232 maternal deaths in Scotland between 1965 and 1971 revealed that $25 \%$ of the women were over 35 years of age and $17 \%$ had had five or more children (Scottish Home and Health Department, 1974). Today, despite the great decline in maternal mortality and the tendency for mothers to be younger and to have smaller families, fatalities still occur in women who have large families and who are too old for safe childbearing. Death followed Caesarean section in 49 cases, an estimated death rate of 1.5 per 1000 Caesarean sections. At a meeting of the British Congress of Obstetrics and Gynaecology (Transactions of XIIth BCOG, 1949) it was reported that the maternal mortality from Caesarean section in the UK was 9.9 per 1000. In 1949 many Caesarean sections were done after a prolonged trial of labour when the risk to the mother was high. For example, of 40 deaths occurring after a trial of labour, 16 were in women who had been in labour for more 
than 48 hours, many of them for over 72 hours. In Scotland in 1965-71, 30 deaths occurred after a trial of labour. The length of labour was recorded in 24 of these and exceeded 48 hours in only one. Today many more Caesarean sections are performed in healthy women primarily for fetal indications without too much hesitation because of the low mortality.

In England and Wales stillbirths became notifiable in 1928 when the stillbirth rate was 42 per 1000 births. It was 30 in the Greater London area and just over 50 in south Wales, where it rose still further to 57 in 1931. It fell steadily between 1935 and 1948, particularly in the regions where it had been highest. Important factors responsible for these changes were the rapid decrease in unemployment as a result of preparation for war and the government's wartime food policy which placed expectant mothers and young children in a priority class for essential foods.

This dramatic and unexpected fall in the stillbirth rate during the second world war focused attention on the importance of a good diet during pregnancy and on the mother's reproductive efficiency in determining the outcome of pregnancy.

In Scotland notification of stillbirths was not introduced until 1939 but the causes were recorded from the beginning, whereas in England and Wales they were not recorded until 1961. From Scottish data, therefore, it could be seen that the wartime fall in the stillbirth rate affected all causes except congenital malformations.

During the first ten years of the National Health Service from 1948 to 1957 , the perinatal mortality rate (PNM) (stillbirths plus deaths in the first six days of life) remained stationary in England and Wales. This was probably the result of three factors:

1. There was less scope for lowering the rate by further improvements in the mother's diet during pregnancy.

2. Considerable time was required to organize a modern maternity service immediately after the war.

3. There was a rise in the death rate from congential malformations and from deaths associated with 'unexplained' low birth weight (LBW) in the cohort of women who started childbearing in 1948-52.

In Aberdeen, on the other hand, the PNM rate continued to fall between 1948 and 1957 because of the much higher standard of obstetric care made possible by a rapid increase in hospital deliveries. By $1952,85 \%$ of all births were taking place in the teaching hospitals round which the newly appointed Regional Hospital Board built its comprehensive regional service. However the PNM rate remained stationary between 1958 and 1961 because during these years the death rate from malformations and that associated with 'unexplained' LBW were at their height and because $15 \%$ of expectant mothers who still elected to have a home confinement were mostly of high parity from social classes IV and V (a very high-risk group). It has been shown (Baird, 1969) that the perinatal mortality rate between 1946-48 and 1964-66 fell more rapidly in Aberdeen . and Dundee than in Edinburgh and Glasgow because in both the former cities a comprehensive $\stackrel{\sigma}{\omega}$ and well-integrated maternity service was organized $\bar{D}$ along similar lines. There may be an optimum size $\stackrel{\Upsilon}{?}$ of population ( 500000 , for example) in which an $\mathcal{U}_{0}$ efficient maternity service can be organized quickly. $\dot{\omega}$ A population of this size is large enough to carry $\vec{\omega}$ the resources necessary for a modern maternity $G$ service.

The factors influencing PNM rates have bee studied in great detail in the city of Aberdeen sing $\overrightarrow{8}$ 1946. For epidemiological purposes perinatal deaths can be divided into two cause group\& 'environmental' where deaths are related primarily to socioeconomic factors, and 'obstetric' whes $\overrightarrow{0}$ deaths are related to complications of pregnane and labour (Baird and Thomson, 1969). Fig. shows that the PNM rate from "environmentat" causes was highest in first pregnancies in 1948-52, in second pregnancies in 1953-57, in third pregnancies in 1958-62, and in fourth and subsequent pregnancies in 1963-67. In the 'obstetric' cause $\triangle$ group the rate in all pregnancies was highest in $\overrightarrow{\overrightarrow{0}}$ 1948-52 and fell steadily in each five-year period 3 except in fourth and subsequent pregnancies where there was little decrease in the rate until 1963-67.

The conclusion to be drawn is that the cohort of women who started childbearing in 1948-52 had a $\stackrel{\circ}{S}$

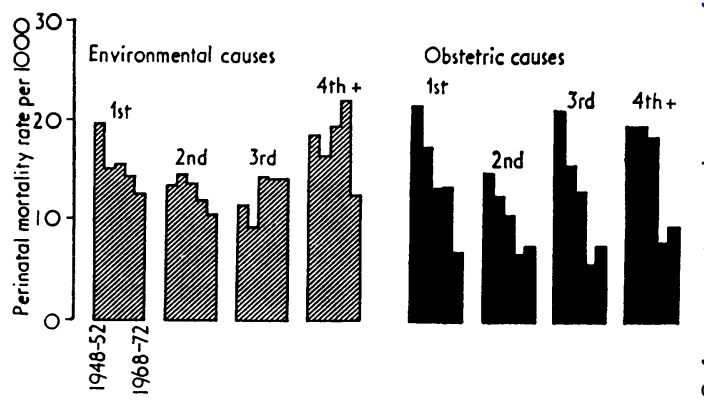

FIG. 1. Perinatal mortality rate from environmental and obstetric causes in 5-year periods, Aberdeen, 1948-52 to 1968-72. 
higher than average death rate from 'environmental' causes in each successive pregnancy. The low rate in fourth and subsequent pregnancies in 1968-72 can probably be explained by the fact that the women with the high rates had finished childbearing by 1963-67. The steady fall in the PNM rate from obstetric causes illustrates the beneficial effect of a high standard of obstetric care. The delay in the fall in the death rate in fourth and subsequent pregnancies until 1963-67 was because before this date $50 \%$ of women in the high parity groups elected to have a home confinement. In the 'environmental' cause group the cohort effect was seen in all three separate causes which constitute this group, but in the 'obstetric' cause group a steady reduction in the death rate from 1948-52 onwards was seen in each pregnancy but most clearly in first pregnancies in relation to difficult labour and placental 'insufficiency'. The death rate associated with pre-eclampsia in first pregnancies did not fall until 1968-72.

Fig. 2 shows that in primigravidae in social classes I-IIIa the PNM rate from environmental causes was highest in 1958-62 and lowest in 1968-72. In social classess IIIb and IIIc a moderate fall occurred in 1968-72 but in classes IV and V the rate rose from 17 in 1963-67 to 27 in 1968-72. The high PNM rate in association with twin pregnancy in social classes IV and V and in single women must be stressed. Although in first births the twinning rate is only slightly lower in classes IV and $\mathrm{V}$ than in classes I-IIIa the perinatal death rate is four times as high. Therefore, out of a total of 103 perinatal deaths in first pregnancies in 1968-72, 11 resulted from LBW associated with twin pregnancy, six out of 43 deaths (14\%) in classes IV and $\mathrm{V}$, and five out of $18(28 \%)$ in single women.

In all social classes death rates from difficult labour and placental insufficiency fell steadily in each five-year period. In social classes I-IIIa, IIIb, and IIIc a moderate fall occurred in the death rate associated with antepartum haemorrhage but there

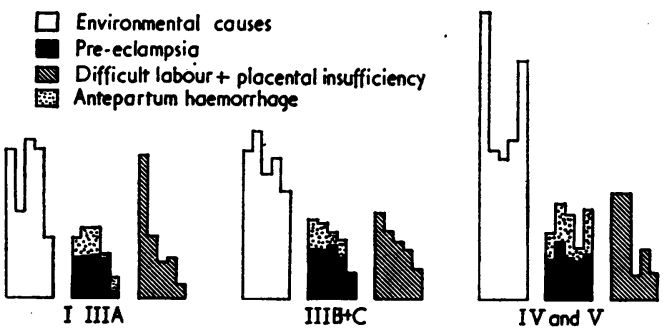

Fig. 2. Perinatal mortality rate first pregnancies by cause group and social class, Aberdeen 1948-52 to 1968-72. was no change in the death rate associated with pre-eclampsia until 1968-72 when it fell sharply. In social classes IV and V no fall in the death rate occurred from either antepartum haemorrhage or pre-eclampsia. What is the explanation for this and why was the fall in the perinatal death rate associated with pre-eclampsia in primigravidae in social classes I-IIIa, IIIb, and IIIc delayed until 1968-72? Fig. 3 shows that in first pregnancies the PNM rate from difficult labour and placental insufficiency fell steadily in every age group in each five-year period. In addition the rapid rise in this rate with increasing age of the mother, which was a striking feature in 1948-52, had almost disappeared by 1968-72. These changes in PNM rates were a direct result of improvements in the standard of obstetric care. The PNM rate from pre-eclampsia also rose with increasing age of the mother and, although less steeply than in other obstetric causes this trend persisted until 1968-72. The pattern of change in the PNM rate in preeclampsia also resembled that in the LBW group in that the rate was highest in the 15-19 age group in 1948-52 and in the 30 and over age group from 1958-62 onwards. All these primigravidae with the high PNM rates associated with LBW and preeclampsia had in common the fact that they were born between 1927 and 1936 when unemployment was at its highest. Severe pre-eclampsia interferes with fetal growth and $80 \%$ of all perinatal deaths from pre-eclampsia in primigravidae between 1948 and 1962 occurred in babies weighing less than $2500 \mathrm{~g}$.

In both $1963-67$ and $1968-72$ all the perinatal deaths from pre-eclampsia were in babies weighing less than $2500 \mathrm{~g}$. Table I shows that the greater part of the reduction in the death rate occurred in babies weighing between 1500 and $2000 \mathrm{~g}$ and

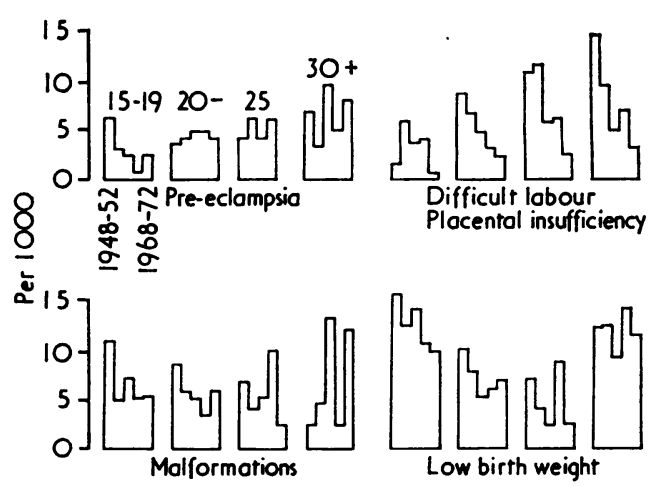

Fic. 3. Perinatal mortality rate first pregnancies by age of mother in 5-year age group, Aberdeen. 
TABLE I

PERINATAL MORTALITY RATE FROM PRE-ECLAMPSIA LEGITIMATE FIRST PREGNANCIES

\begin{tabular}{|c|c|c|c|c|c|c|}
\hline \multirow[b]{2}{*}{$\begin{array}{c}\text { Birth Weight } \\
\text { (Grams) }\end{array}$} & \multicolumn{3}{|c|}{$1963-67(4 \cdot 3$ per 1000$)$} & \multicolumn{3}{|c|}{$1968-72(2 \cdot 1$ per 1000$)$} \\
\hline & $\begin{array}{l}\text { Births } \\
\text { (No.) }\end{array}$ & $\begin{array}{c}\text { PN } \\
\text { Deaths }\end{array}$ & $\begin{array}{c}\text { Rate } \\
\%\end{array}$ & \begin{tabular}{|l|} 
Births \\
(No.). \\
\end{tabular} & $\begin{array}{c}\text { PN } \\
\text { Deaths }\end{array}$ & $\begin{array}{c}\text { Rate } \\
\%\end{array}$ \\
\hline$<1000$ & 4 & $3(1)$ & 75 & 1 & $1(1)$ & 100 \\
\hline $1000-1499$ & 9 & $9(1)$ & 100 & 11 & 7 (2) & 64 \\
\hline 1500-1999 & 17 & $6(5)$ & 35 & 15 & $1(1)$ & 7 \\
\hline $2000-2499$ & 32 & $2(1)$ & 6 & 24 & $\mathbf{0}$ & 0 \\
\hline Total $<2500$ & 62 & $20(8)$ & 32 & 51 & $9(4)$ & 18 \\
\hline
\end{tabular}

Deaths 0-6 days are given in parentheses affected stillbirth and first week deaths equally. $\infty$ Table II shows that the perinatal death rate from $\triangle$ pre-eclampsia was $50 \%$ less in 1968-72 than in 3 1963-67 due almost entirely to a fall in the rate in $\stackrel{0}{?}$ classes I-IIIc in babies weighing $1500 \mathrm{~g}$ or more. On the other hand the perinatal death rate associated $\stackrel{0}{?}$ with LBW was only slightly lower in 1968-72 than in 1963-67 because the fall in the death rate in $\overline{\bar{T}}$ classes I-IIIc was accompanied by a marked rise $\frac{\infty}{\sigma}$ in the rate in classes IV and V and in illegitimate $\unrhd$ babies weighing less than $1500 \mathrm{~g}$. Table III shows that in all social classes the fall in the number of $\overrightarrow{0}$ deaths (and in the death rate) from pre-eclampsia ? occurred mostly in women who were over the age of $\vec{\omega}$

TABLE II

PERINATAL MORTALITY RATE FROM PRE-ECLAMPSIA AND LOW BIRTH WEIGHT FIRST PREGNANCIES ABERDEEN 1963-67 AND 1968-72 BY BIRTH WEIGHT AND SOCIAL CLASS

\begin{tabular}{|c|c|c|c|c|c|c|c|c|c|c|c|c|}
\hline \multirow{2}{*}{$\begin{array}{c}\text { Birth } \\
\text { Weight } \\
\text { (Grams) }\end{array}$} & \multicolumn{6}{|c|}{$1963-67$} & \multicolumn{6}{|c|}{$1968-72$} \\
\hline & I-IIIA & IIIB & IIIC & IV + V & Illegitimate & Total & I-IIIA & IIIB & IIIC & $I V+V$ & Illegitimate & Total \\
\hline $\begin{array}{c}\text { Pre-eclampsia } \\
<1000 \\
1000-1499 \\
1500-1999 \\
2000-2499\end{array}$ & $\begin{array}{l}1 \\
3 \\
2 \\
0\end{array}$ & $\begin{array}{l}2 \\
2 \\
2 \\
0\end{array}$ & $\begin{array}{l}0 \\
1 \\
1 \\
1\end{array}$ & $\begin{array}{l}0 \\
3 \\
1 \\
1\end{array}$ & $\begin{array}{l}1 \\
1 \\
3 \\
0\end{array}$ & $\begin{array}{r}4 \\
10 \\
9 \\
2\end{array}$ & 1 & $\begin{array}{l}1 \\
1\end{array}$ & 1 & $\begin{array}{l}4 \\
1\end{array}$ & $\begin{array}{l}2 \\
1\end{array}$ & $\begin{array}{ll}1 & \overline{0} \\
9 & \stackrel{\mathbb{D}}{\circ} \\
1 & \stackrel{\bigcirc}{\mathbb{D}} \\
1 & \stackrel{Q}{Q}\end{array}$ \\
\hline Total $<2500$ & 6 & 6 & 3 & 5 & 5 & 25 & 1 & 2 & 1 & 5 & 3 & 12 ర \\
\hline PNM rate & $4 \cdot 4$ & \multicolumn{2}{|c|}{$4 \cdot 6$} & $4 \cdot 1$ & $9 \cdot 5$ & $4 \cdot 7$ & 0.7 & \multicolumn{2}{|c|}{$1 \cdot 8$} & $4 \cdot 5$ & $4 \cdot 6$ & $\overline{2.48}$ \\
\hline $\begin{array}{c}\text { Low birth } \\
\text { weight } \\
<1000 \\
1000-1499 \\
1500-1999 \\
2000-2499\end{array}$ & $\begin{array}{l}4 \\
3 \\
3 \\
1 \\
1\end{array}$ & $\begin{array}{l}4 \\
2 \\
1 \\
0\end{array}$ & $\begin{array}{l}5 \\
5 \\
2 \\
0\end{array}$ & $\begin{array}{l}8 \\
4 \\
0 \\
2\end{array}$ & $\begin{array}{l}0 \\
1 \\
0 \\
1\end{array}$ & $\begin{array}{r}21 \\
15 \\
6 \\
4\end{array}$ & $\begin{array}{l}0 \\
0 \\
1 \\
2\end{array}$ & $\begin{array}{l}0 \\
2 \\
0 \\
2\end{array}$ & $\begin{array}{l}\mathbf{2} \\
\mathbf{0} \\
\mathbf{2} \\
\mathbf{0}\end{array}$ & $\begin{array}{l}9 \\
7 \\
1 \\
2\end{array}$ & $\begin{array}{l}6 \\
3 \\
0 \\
1\end{array}$ & \\
\hline Total $<2500$ & 11 & 7 & 12 & 14 & 2 & 46 & 3 & 4 & 4 & 19 & 10 & 40 \\
\hline PNM rate & $8 \cdot 0$ & \multicolumn{2}{|c|}{$9 \cdot 7$} & $11 \cdot 5$ & $3 \cdot 8$ & $8 \cdot 7$ & $2 \cdot 2$ & \multicolumn{2}{|c|}{$4 \cdot 5$} & $17 \cdot 2$ & $15 \cdot 2$ & $7 \cdot 9$ \\
\hline
\end{tabular}

TABLE III

PERINATAL MORTALITY RATE FROM PRE-ECLAMPSIA AND LOW BIRTH WEIGHT FIRST PREGNANCIES 1963-67 AND 1968-72 BY AGE AND SOCIAL CLASS

\begin{tabular}{|c|c|c|c|c|c|c|c|c|c|c|c|}
\hline \multirow{2}{*}{\multicolumn{2}{|c|}{ Social Class }} & \multicolumn{5}{|c|}{ 1963-67 } & \multicolumn{5}{|c|}{$1968-72$} \\
\hline & & $<20 \mathrm{Yr}$ & $20-24 \mathrm{Yr}$ & $25-29 \mathrm{Yr}$ & $30+Y_{\mathbf{r}}$ & All ages & $<20 \mathrm{Yr}$ & $20-24$ Yr & $25-29 \mathrm{Yr}$ & $30+\mathbf{Y r}$ & All Ages \\
\hline \multirow[t]{2}{*}{$\begin{array}{l}\text { Pre-eclampsia } \\
\text { I+IIIa } \\
\text { IIIb, and Iilc } \\
\text { IV and V ... } \\
\text { Illegitimate }\end{array}$} & \multirow[t]{2}{*}{$\begin{array}{l}\ddot{x} \\
\cdots \\
\cdots\end{array}$} & $\begin{array}{l}1 \\
1\end{array}$ & $\begin{array}{l}\mathbf{6} \\
\mathbf{3} \\
\mathbf{2} \\
\mathbf{1}\end{array}$ & $\begin{array}{l}\mathbf{2} \\
\mathbf{2} \\
\mathbf{2} \\
\mathbf{2}\end{array}$ & $\begin{array}{l}2 \\
1\end{array}$ & $\begin{array}{l}8(5 \cdot 9) \\
7(3 \cdot-3) \\
5(4 \cdot 1) \\
5(9 \cdot 5)\end{array}$ & $\begin{array}{l}2 \\
1 \\
2\end{array}$ & $\begin{array}{l}1 \\
3\end{array}$ & 1 & 1 & $\begin{array}{l}1(0 \cdot 7) \\
3(1 \cdot 6) \\
5(4 \cdot 5) \\
3(4 \cdot 5)\end{array}$ \\
\hline & & $\begin{array}{c}2 \\
(1 \cdot 4)\end{array}$ & $\begin{array}{c}12 \\
(4 \cdot 9)\end{array}$ & $\begin{array}{c}8 \\
(8 \cdot 3)\end{array}$ & $\left(\begin{array}{c}3 \\
(7 \cdot 0)\end{array}\right.$ & $25(4 \cdot 7)$ & $\begin{array}{c}5 \\
(3 \cdot 0)\end{array}$ & $\left(\begin{array}{c}4 \\
(1 \cdot 6)\end{array}\right.$ & $\begin{array}{c}1 \\
(1 \cdot 2)\end{array}$ & $\begin{array}{c}2 \\
(7 \cdot 2)\end{array}$ & $12(2 \cdot 4)$ \\
\hline \multirow[t]{2}{*}{$\begin{array}{l}\text { Low birth weight } \\
\text { I+ IIIa } \\
\text { IIIb and IIIc } \\
\text { IV and V ... } \\
\text { Illegitimate }\end{array}$} & $\begin{array}{l}. . \\
\because \\
\because\end{array}$ & $\begin{array}{l}1 \\
7(13) \\
4(9) \\
2(8)\end{array}$ & $\begin{array}{l}3(5) \\
7(6) \\
6(12) \\
0\end{array}$ & $\begin{array}{l}6(15) \\
4(12) \\
0 \\
0\end{array}$ & $\begin{array}{l}1 \\
1 \\
4 \\
0\end{array}$ & $\begin{array}{l}11(8) \\
19(9) \\
14(12) \\
2(4)\end{array}$ & $\begin{array}{l}0 \\
2(4) \\
9(22) \\
4(11)\end{array}$ & $\begin{array}{l}2(5) \\
5(5) \\
7(13) \\
6(25)\end{array}$ & $\begin{array}{l}1 \\
1 \\
0 \\
0\end{array}$ & $\begin{array}{l}\mathbf{0} \\
\mathbf{0} \\
\mathbf{3} \\
\mathbf{0}\end{array}$ & $\begin{array}{r}3(2) \\
8(5) \\
19(17) \\
10(15)\end{array}$ \\
\hline & & $\begin{array}{l}14 \\
(10 \cdot 8)\end{array}$ & $\stackrel{16}{(6 \cdot 6)}$ & $\begin{array}{l}10 \\
(10 \cdot 4)\end{array}$ & $\begin{array}{c}6 \\
(14 \cdot 3)\end{array}$ & $46(8 \cdot 8)$ & $\begin{array}{l}15 \\
(10 \cdot 1)\end{array}$ & $\stackrel{20}{(8 \cdot 0)}$ & $\begin{array}{c}2 \\
(2 \cdot 5)\end{array}$ & $\begin{array}{c}3 \\
\left(10^{3} \cdot 8\right)\end{array}$ & $40(7 \cdot 9)$ \\
\hline Numbers & .. & 1391 & 2431 & 960 & 426 & 5208 & 1488 & 2512 & 811 & 277 & 5088 \\
\hline
\end{tabular}


25. The fall in the death rate in LBW babies in classes I-IIIc occurred in all age groups but was greatest in those over the age of 25 , whereas the rise in the rate in 1968-72 in classes IV and V and in illegitimate babies occurred in those under the age of 25 .

In Scotland the stillbirth rate from anencephalus rose in women born between 1927 and 1931. In mothers of 15-19 years of age the rise in the rate began in 1946 and rose to over 3.9 per 1000 in 1952 and was maintained at this level until 1965 in babies born to women born as late as 1947-50, a period of 19 years.

In the 20-24 age group the rise in the rate began in 1951 and reached a level of 3.0 per 1000 in 1954 which was maintained until 1963 in babies born to women who themselves were born as late as 1939-43, a period of 12 years. In the 25-29 age group the rise in the rate began in 1956 and reached its highest level of 2.7 in 1959 at which level it was maintained until 1963 in babies born to women who themselves were born not later than 1934-38, a period of only seven years. It seems therefore that babies born during the worst of the industrial depression received damage which from 1947 onwards lowered their reproductive efficiency as measured by a high perinatal death rate from malformations of the central nervous system (CNS).

The damage was most severe and could be demonstrated for many more years in women who had their first baby between the ages of 15 and 19 . Altogether $40 \%$ of them came from classes IV and $\mathrm{V}$ and only $10 \%$ from classes I-IIIa. The risk of damage was least and was sustained for a much shorter period of years in the children of women who started childbearing between the ages of 25 and 29 because $44 \%$ of the women in this age group were from classes I-IIIa and only $16 \%$ from classes IV and V.

In all social classes the perinatal death rate from all causes is lowest in the 25-29 age group.

In Aberdeen the rise in the perinatal death rate associated with LBW in first births in social classes IV and V and illegitimate babies in 1968-72 occurred in the 15-19 and 20-24 age groups in women born in 1949-57 and 1944-52 respectively (Baird, 1974a). They were, therefore, the daughters of women who had had high rates from malformations and LBW 20 years earlier. One might postulate that damage sustained as a result of depressed social conditions from 1927 onwards had affected two generations of women in social classes IV and V. It seems that the timing of malnutrition may be as important as its severity. For example, it is thought that severe and chronic malnutrition due to either low protein alone or low protein and low calories may start to influence fetal weight at the time of implantation of the blastocyst (Ciba Foundation Symposium, 1974). A poor endometrial response will result in the development of a small placenta which will be unable to meet the demands of the fetus when it starts to increase in weight. This concept might help to explain the high incidence of malformations of the CNS and of LBW babies born to women from 1946 onwards who were themselves born from 1927 onwards.

With regard to changes in the perinatal mortality rate from pre-eclampsia Dunlop has shown that in the Simpson Memorial Pavilion in Edinburgh the death rate in cases of pre-eclampsia, which had varied between 6 and $9 \%$ between 1951 and 1965, fell to $4 \%$ in 1966 , the years in which the death rate from this cause started to fall in Aberdeen. He is of the opinion that the fall in the death rate in Edinburgh, which has persisted, is probably due to a number of factors and not solely the result of improved obstetric and pediatric care. Some of these factors may be the decrease of $26 \%$ in the number of primigravidae over the age of 25 in 1968-72 compared with 1963-67 and a general increase in the level of health and physique of young women in social classes I-IIIc. In the past primigravidae in classes IV and V benefited from the fact that they were young. It is possible that today many of them are too young for efficient childbearing. In those whose first pregnancy occurs before the age of 20 there has been a great increase in induced abortion, illegitimacy, prenuptial conception, forced marriage, and divorce within four years of marriage (Baird, 1975). Although the relative importance of these and other factors cannot be measured accurately the fact remains that the social class differences in the perinatal mortality rate in first pregnancies in Aberdeen have increased. Between 1948-52 and 1968-72 the overall PNM rate fell by $50 \%$, by $73 \%$ in classes I-IIIa, $47 \%$ in classes IIIb and IIIc, and $22 \%$ in classes IV and V.

\section{Geographical Differences in Perinatal MORTALITY}

The failure of the PNM rate in Britain to improve between 1948 and 1957 and the persistence of the regional differences caused the National Birthday Trust to carry out an inquiry into perinatal mortality in 1958. For this purpose Illsley (1963) divided Britain into three zones-north, central, and south. He showed that women were tallest in the south zone and shortest in the north, and in each zone 
were taller in rural than in urban areas. Women were shortest and the PNM rate highest (41 per 1000) in urban areas in the north zone. They were tallest and the PNM rate lowest (21 per 1000) in rural areas in the south zone.

Perinatal death rates from environmental causes were highest in urban areas in the north zone and lowest in rural areas in the south zone. There was much less difference from north to south in death rates from obstetric causes which were slightly lower in urban than in rural areas. It was concluded that the higher rates in the north zone were due primarily to poorer health and physique of mothers in the north, especially in urban areas, and that there was need to improve the standards of obstetric care generally, especially in rural areas.

In Britain the height distribution of young adults is still a valuable index of the level of health and physique. It rests on the assumption that many adults have not reached their potential height. Some of the tallest women in Scotland are to be found in the Hebrides and Wester Ross. For example, in the $1960 \mathrm{~s} 50 \%$ were $162 \mathrm{~cm}$ or more in height compared with $28 \%$ in the city of Aberdeen. Crofters in the north west Highlands may be less affluent in terms of actual money than many manual workers in the cities but they are better grown and healthier, and more efficient reproducers. The Caesarean section rate in primigravidae in Aberdeen varies from $4 \%$ in tall women (162 cm or more) to $10 \%$ in short women (less than $154 \mathrm{~cm}$ ). This is partly due to the association between short stature and contraction and flattening of the brim of the pelvis. The Caesarean section rate for fetal distress and poor fetal growth also rises much earlier in short than in tall women with increasing maternal age. This suggests that good health and physique can postpone the deleterious effect of increasing age on reproductive efficiency, especially in first pregnancies.

The perinatal mortality rate in Britain is considerably higher than in some European countries. For example, in the early 1960s the rate in the Netherlands was 23 per 1000 compared with 26 in England and Wales, and 29 in Scotland. Much of this difference was due to the fact that the PNM rate from congenital malformations was twice as high in England and Wales and three times as high in Scotland as in the Netherlands. The comparatively low PNM rate from malformations of the CNS in the Netherlands (Baird, 1974b) suggests that social conditions have been much more favourable than in Britain. Yet in $\mathbf{1 8 8 0}$ the infant mortality rate in the Netherlands was 180 and in Scotland 120. At that time there was great poverty and mass unemployment in the Netherlands but thereafter the rate fell steadily to reach 50 in 1940 and 12 in 1972 . In Scotland the rate rose from 120 in 1880 to 140 in 1900, and in England and Wales from 140 to 160 . Thereafter it fell in both countries, but more rapidly in England and Wales, to reach 68 in 1931 compared with 106 in Scotland. In Scotland the infant mortality rate was much higher in the four large cities than in the rest of the country. In Aberdeen the rate fell rapidly to reach 12 per 1000 by 1972. In Glasgow in 1972 the rate was 25.3 per 1000 ( $26 \%$ above the national rate).

The city of Glasgow and the whole of Clydeside were almost totally committed to heavy industries in the nineteenth century. Many of the inhabitants of Glasgow lived in degradation, crowded together in slum tenements. Smoke from factories and domestic fires shut out the sun and polluted the atmosphere. Rickets was common and Glasgow surgeons became renowned for their skill in performing osteotomy to straighten crooked legs. It is difficult to identify any particular aspect of Glasgow' poor environment which was responsible for the much greater damage to health and physique of the inhabitants than that which occurred in the Netherlands. We know that Britain was the firs country to develop heavy industries. Industrializatio $\overrightarrow{0}$ came quickly without consideration for the working. ov and living conditions of the men and women whor constituted the work force. In Holland industrialization occurred later when the disadvantages and dangers had become more apparent. Better techniques were available in factories and legislation existed to protect health. Even in the small city of Aberdeen where the infant mortality rate has fallen steadily since the end of the first world war and is now 12 per 1000 (as low as in the Netherlands) young mothers are on average more than $5.1 \mathrm{~cm}$ shorter than Dutch women.

In 1968-72 the PNM rate in Scotland was 25 per 1000 varying from $26 \cdot 3$ in 1968 to $24 \cdot 1$ in 1972 . Fig. 4 shows that the lowest rates (less than 20 per 1000 ) were in the counties of Aberdeen, Kincardine, and Angus and the highest (more than 25) were in the counties of Lanark, Ayr, Renfrew, Stirling, West and East Lothian, Clackmanan, Dunbarton, and Fife. The PNM rate was also high in Sutherland and Caithness. The rate was lowest in Aberdeen, Kincardine, and Angus because of the well-organized regional obstetric services and because of the large agricultural hinterland where the level of health and physique was better than in the cities. This was most obvious in the prosperous farming areas in the county of Angus where, in 1968-72, the PNM 


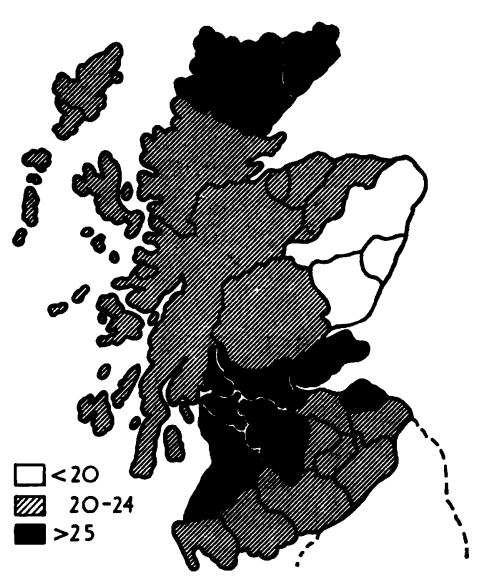

Fig. 4. Perinatal mortality rate per 1000 births, 1968-72.

rate was $16 \cdot 8$ per 1000 . In the county of Lanark nearly $60 \%$ of the births occurred in Glasgow where the PNM rate was 30 per 1000 . The rate for the rest of the county was also high $(28 \cdot 3)$ because it was heavily industrialized. The high PNM rate in Scotland was due to the fact that $68 \%$ of the population lived in the industrial counties where the rate was more than 25 per 1000 . Only $13 \%$ lived in the counties where the rate was less than 20.

In England and Wales the PNM rate in 1972 was 21.7. It was less than 20 in the hospital regions of East Anglia, three of the four Metropolitan regions, Wessex, South Western, and Oxford. It was more than 23 in the Newcastle, Leeds, Manchester, Birmingham, and Liverpool regions. Only $38 \%$ of all births occurred in the regions with a PNM rate of more than 23 and $40 \%$ of births in regions where it was less than 20.

Difficult labour is the only cause of stillbirth in the obstetric group in the Aberdeen classification, and congenital malformation the only cause in the environmental group which can be identified with confidence in the Scottish data. Fig. 5 shows that in Scotland the social class difference in the stillbirth rate from difficult labour is relatively small and the rate of fall has been the same in all social classes. The stillbirth rate from malformations in 1950-52 was much lower in social classes I and II than in classes IV and V and fell substantially between 1953-57 and 1960-62. In social classes IV and V the rate rose in 1953-57 and did not fall again until 1965-67. There is little doubt that a similar social class difference occurred in the stillbirth rate associated with 'unexplained' LBW but this information could not be abstracted from the national

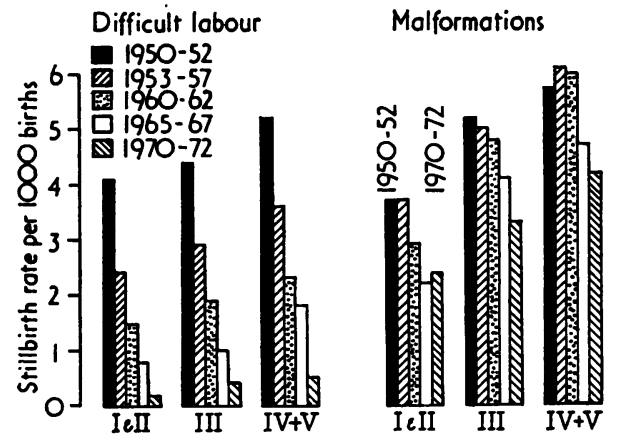

Fig. 5. Stillbirth rate difficult labour and malformations, Scotland.

data. The delay in the fall in the stillbirth rate from environmental causes in social classes IV and V is probably related to the fact that these women, born during the worst of the industrial depression in 1927-36, tended to have large families so that many of those who started having children in 1948-52 did not complete their childbearing before 1967.

The depressed socioeconomic conditions of Scotland, especially in Glasgow and the surrounding industrial towns on Clydeside, explain why the stillbirth rate from malformations has been so high and remained high for so long. In the Liverpool Hospital Region, where socioeconomic conditions resembled those on Clydeside, the stillbirth rate from malformations was also high (3.9 per 1000 in 1963 and 3.7 in $1971,30 \%$ above the national average).

The great difference between the two countries is that in Scotland $68 \%$ of all births occur in areas where the rates are high compared with only $23 \%$ in England and Wales.

The infant mortality rate in Glasgow was $25 \cdot 3$ per 1000 in $1972(30 \%$ less than in 1962$)$ but $26 \%$ higher than the national rate. The PNM rate in Glasgow is still $30 \%$ higher than the combined rate for Edinburgh, Dundee, and Aberdeen.

Control of Conception and Family Planning

In Scotland 50 years ago $25 \%$ of all maternal deaths were due to septic abortion, many being criminal. In the Royal Maternity Hospital in Glasgow one-third of all maternal deaths were in women who had already had six or more children. Despite this there was no serious discussion on the question of contraception or sterilization. Termination of pregnancy was seldom undertaken (never in Roman Catholic patients even to save the mother's life). 
The Observer in the early 1930s published a forthright article defending the right of women to rebel against excessive childbearing and pointing out that the high abortion rate did not come from any refusal of women to perform their normal function of childbearing. 'Where poverty and malnutrition are realities, it is the very good mother and not the bad one who dreads the coming of too many children. The Public Health Services should face up to the whole problem of pregnancy and the alternatives of birth control and abortion'. In Aberdeen a contraceptive clinic was financed and opened in 1925 by Mrs Fenella Paton who had been inspired by the writings of Marie Stopes, one of the pioneers of contraception in Britain. The local health authority assumed responsibility for the clinic in 1946 and it formed part of the local authority postnatal services. Because those most in need did not take advantage of the contraceptive service, therapeutic abortion was offered in the most desperate cases. Over 200 Aberdeen women (twothirds of whom had had seven or more children) had a therapeutic abortion and sterilization between 1938 and 1947 . The results were so satisfactory that the use of this measure was extended to younger women with smaller families and by 1961 more than $2 \%$ of pregnancies in married women were terminated annually. Since the passing of the Abortion Act in 1967 the incidence of therapeutic abortion in married women has increased steadily to just over $7 \%$ in 1972.

The introduction of oral contraception in 1964 immediately increased the number of married women attending the family planning clinics (from over 200 first attenders in 1964 to 1100 in 1972). Probably as many attended their family doctor for contraceptive advice. The number of sterilizations increased from 200 to 600 per annum between 1961 and 1972, and in addition, in 1970-72 more than $\mathbf{5 0 0}$ men had vasectomy performed under the National Health Service and probably as many more as private patients. These figures refer to a population where there are fewer than 1500 first pregnancies each year.

This extension of family planning developed steadily towards meeting the need until the early 1960 s when a sudden increase in pregnancies in single women occurred and presented an acute and new problem. The illegitimacy rate in Scotland was much higher than it had been in England and Wales before the last world war. It was higher in rural than urban areas and occurred mostly in unskilled manual workers. The rise in the rate began in London in 1958 in young women in non-manual occupations (Illsley and Gill, 1968). In Scotland it began in 1963 and in Aberdeen the number of therapeutic abortions in illegitimate pregnancies rose from $6 \%$ in 1964 to $52 \%$ in 1972 . During these years the incidence of 'spontaneous' abortion fell from 16 to $8 \%$ suggesting that in the earlier years many of the abortions, diagnosed as spontaneous, were not in fact spontaneous. In Aberdeen in 1972, 434 pregnancies $(15 \%$ of all pregnancies reported) were terminated. Of these $58 \%$ were illegitimate, the great majority being first pregnancies in single women. While there is general agreement that everything should be done to reduce the number of pregnancies in single women, there has been considerable resistance to making contraceptives too easily available lest this should be taken as approval of extramarital sexual intercourse and 'promiscuity'. From 1967 the local authority clinics in Aberdeen have been open to single women and the number who attended for the first time rose from 50 in 1967 to 1300 in 1972. In $1968-71,58 \%$ were from the professional classes and only $16 \%$ from manual occupations. On the other hand of those referred foro abortion $25 \%$ had professional occupations, $25 \%$ clerical, and $46 \%$ manual. There were $4 \%$ who were still attending school.

\section{EFFECT ON THE Number OF BiRTHS}

Fig. 6 shows that the number of first births. which in Aberdeen had varied between 1000 an 9 1100 for many years, fell to less than 1000 in 1969 and 1970, at a time when one would have expected a rise in the numbers because of the increase in births in 1946-48. If no therapeutic abortions had been done in 1971 the number of first births would have been 1200 . The fall in the number of first births in 1972 was not unexpected in view of the relatively small number of first births in 1950-51. The number

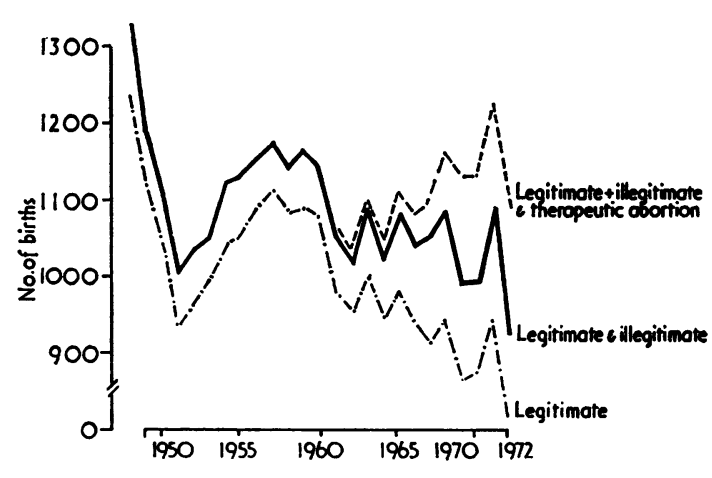

Fig. 6. First pregnancies, 1948-72, Aberdeen. 
of second births has also decreased since 1966, an indirect effect of the number of first pregnancies terminated. It must take some time for a young woman who has had an abortion to recover from the shock of the experience, marry, and give birth to a first baby, let alone a second. There is also evidence that the greater use of contraceptives, especially the 'pill', is resulting in a longer interval between marriage and the first pregnancy (Baird, 1975). In Aberdeen 721 fewer births occurred in 1972 than in 1965 (a drop of $23 \%$ ). One-quarter of these were due to fewer fifth or later pregnancies. Only one-quarter of the women having a fifth pregnancy in 1972 had four surviving children (less than $1 \%$ of all births); the rest had had previous abortions or perinatal deaths and were planning a family of not more than two or three children. Of these $50 \%$ asked to be sterilized and had a postpartum sterilization performed. The percentage was the same in all social classes. In Aberdeen there is now very little social class difference in the percentage of fifth or later pregnancies because the incidence in social classes IV and $\mathrm{V}$ has fallen by as much as $75 \%$ since 1961 .

Table IV shows that in 1968 the percentage of women having a fifth or later child varied from $25 \%$ in the Republic of Ireland to $2.4 \%$ in Aberdeen.

TABLE IV

PERCENTAGE DISTRIBUTION OF BIRTHS BY NUMBER OF PREVIOUS CHILDREN

\begin{tabular}{|c|c|c|c|c|c|}
\hline $\begin{array}{l}\text { No. of } \\
\text { Previous } \\
\text { Children }\end{array}$ & $\begin{array}{l}\text { Republic } \\
\text { of Ireland } \\
1968\end{array}$ & $\begin{array}{c}\text { Glasgow } \\
1968\end{array}$ & $\begin{array}{c}\text { Scotland } \\
1968\end{array}$ & $\begin{array}{c}\text { Engiand } \\
\text { and Wales } \\
1968\end{array}$ & $\begin{array}{c}\text { Aberdeen } \\
1969\end{array}$ \\
\hline $\begin{array}{l}0 \\
1 \\
2 \\
3 \\
4+ \\
\text { All }\end{array}$ & $\begin{array}{r}26 \cdot 2 \\
20 \cdot 3 \\
16 \cdot 1 \\
12 \cdot 3 \\
25 \cdot 1 \\
100 \cdot 0\end{array}$ & $\begin{array}{r}32 \cdot 6 \\
25 \cdot 4 \\
16 \cdot 7 \\
10 \cdot 3 \\
15 \cdot 0 \\
100 \cdot 0\end{array}$ & $\begin{array}{r}36 \cdot 0 \\
29 \cdot 8 \\
17 \cdot 0 \\
8 \cdot 6 \\
8 \cdot 5 \\
100 \cdot 0\end{array}$ & $\begin{array}{r}38 \cdot 2 \\
32 \cdot 5 \\
15 \cdot 9 \\
7 \cdot 0 \\
6 \cdot 4 \\
100 \cdot 0\end{array}$ & $\begin{array}{r}42 \cdot 8 \\
35 \cdot 6 \\
14 \cdot 4 \\
4 \cdot 8 \\
2 \cdot 4 \\
100 \cdot 0\end{array}$ \\
\hline
\end{tabular}

\section{Changing Attitudes to Family Size}

The fact that the fall in the percentage of births in the high parity groups was greatest in social classes IV and V reflects a great change in attitude to family planning.

As stated earlier, women of the previous generation, especially those in social classes IV and V, were either resigned to having large families or lacked the confidence to ask for help to escape the tyranny of continuous childbearing. Today sterilization is being requested by women in all social classes after the second or third child. Husband and wife are prepared to accept responsibility for their decisions.
Twenty years ago one had to put forward the idea of sterilization cautiously but today it may be the mother in her middle twenties with perhaps two children who persuades the family doctor or the obstetrician that sterilization is desirable. Even more remarkable is the willingness of husbands from all social classes to have vasectomy performed. The reason given for limitation of family size is almost invariably the cost of living and giving the children a 'good start in life'. For some women a return to work outside the home is essential to accomplish this. Others wish to continue a career in business or a profession. Very few give over-population as a factor influencing their decision on family size.

The doctor's role has changed as society has changed. He should now act more in an advisory capacity by helping the patient to make the wisest decision for her in the light of all the facts both medical and social. One should not lose sight of the fact that the mother's commitment is not only for the nine months of the pregnancy but for the next 16 years at least while the child is growing up. The quality of the environment in the home largely determines the opportunities open to the individual.

The doctor-patient relationship differs in the case of a request for abortion from that in most other circumstances, because the patient can make the diagnosis that she is pregnant and can assess her personal situation. I have gradually come round to the view that abortion on request is the most realistic attitude to adopt in the present state of society and that while doctors should not be forced to recommend or perform abortions if they have deeply held convictions that such a procedure is wrong, they have a duty to help the patient to have access to doctors whose views are more in line with her own. I think that more patients (especially immature and inexperienced women) would turn to their family doctor for help if they were confident that he would discuss their problem dispassionately even if, in the end, he did not agree with their point of view.

Fig. 7 shows that the birth rate in England and Wales was lower than in Scotland from 1926 onwards and the fall during the industrial depression in the early 1930s was greater. From 1965 the birth rate in Scotland has fallen more quickly than in England and Wales and in 1972 it was only slightly higher. The birth rate in Aberdeen has fallen sooner and more quickly than in either Scotland or England and Wales as a result of a liberal policy of postpartum sterilization and therapeutic abortion. The introduction of oral contraception in 1964 and of vasectomy in 1970 has also played a part. The birth rate per thousand fell from $17 \cdot 4$ in 1965 to $12 \cdot 8$ in 


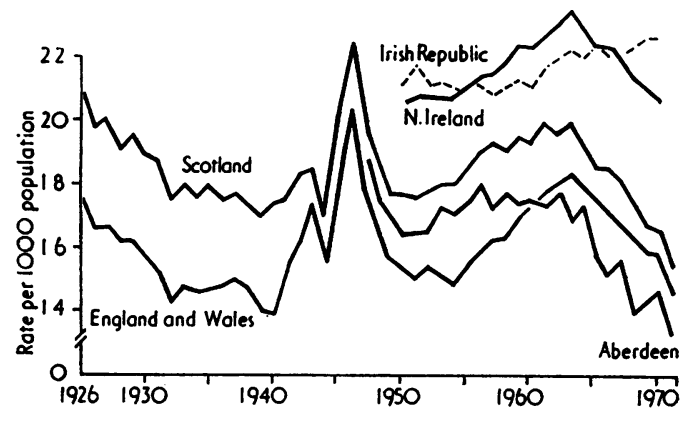

Fig. 7. Birth rate per 1000 of population.

1973 , and the number of fifth or later pregnancies by $75 \%$. The reduction in the birth rate in Aberdeen has resulted in many benefits; very low perinatal and infant mortality rates, better health of mothers and children, smaller classes in schools and an adequate supply of teachers, fewer problem children, and a low incidence of juvenile delinquency.

Much has been made of the dangers of abortion. With regard to the risk of death, data from England and Wales show that the maternal mortality rate after abortion (whether spontaneous or induced) has fallen steadily since 1966 . For example the rate per 100000 births has fallen from 6.2 in 1963-66 to 3.8 in $1969-72$. It will almost certainly fall further as more terminations are performed earlier in pregnancy.

One hopes that fewer unwanted children will be born and the population maintained at replacement level with less reliance on abortion. However in Sweden where the population has been stable for many years, both the illegitimacy and the abortion rates have remained high.

\section{THe Future}

In Sweden the PNM rate is 16 per 1000 , the lowest in Europe. This is due to the uniformly high standard of health and physique of Swedish women, the standard of obstetric and paediatric care, and the fact that almost all births take place in modern hospitals. This rate has been attained in a few areas in the UK where these prerequisites exist and more generally in social classes I and II, but the national rate in 1972 in England and Wales was 22.3 and in Scotland 24.1. In the city of Aberdeen the PNM rate was 20 , and if deaths from malformations are excluded, $85 \%$ of the remaining perinatal deaths were in babies weighing $2500 \mathrm{~g}$ or less. Great attention is, therefore, being paid to measuring the growth and well-being of the fetus during pregnancy, deciding the optimum time for induction of labour, continuous monitoring of the fetal heart in labour, and the use of the Caesarean section where there is any doubt about the baby's ability to survive the hazards of labour.

The treatment of the LBW baby in special nurseries has become very sophisticated, survival rates have risen, and there are reports that the risk of cerebral damage and mental subnormality resulting from immaturity may be less.

A majority of women today do not have more than two children and are prepared to take trouble to obtain the best standard of care in childbirth to avoid complications, especially those which may harm the baby. The mother may have a choice of methods for the relief of pain in labour-a change from the time when all that was available was a little chloroform at the end.

It is doubtful if a first-class day and night maternity service can be given except in large maternity units staffed by specialists. While in such surroundingsp technical excellence and great safety can be achieved $\vec{c}$ it is not possible, even with the most efficiend organization, to guarantee to the patient continuit $\mathbb{B} \frac{\mathbb{D}}{\mathbb{D}}$ of personal supervision by either nurses or doctorso For reasons of economy, if for no other, the mother's 은 stay in hospital is short and if her baby is of low $\overrightarrow{0}$ birth weight and requires skilled paediatric care. of she has limited and intermittent contact with it We do not know how far her psychological needs can be satisfied and what effect this may have on both mother and child.

In cities the vast majority of confinements take place in large hospitals under the care of specialists. In rural areas most babies are born in small maternity units conveniently placed for the patient and the family doctor. With close integration of the work of all the members of the obstetric service high-risk cases can be selected for delivery in specialist units to which patients with unexpected complications can be transferred quickly and after delivery can be returned to their local hospital for convalescence. In these circumstances the PNM rate in rural areas may be lower than that for urban areas. (For example the PNM rate in Aberdeenshire in 1968-72 was $18 \cdot 2$ per 1000 compared with $20 \cdot 8$ in the city of Aberdeen.)

If 'normal' obstetric practice in the cities were N done by general practitioner obstetricians who had received the necessary postgraduate training in $N$ obstetrics the results might be equally good. Special $\omega$ administrative arrangements would have to be made to enable the GP obstetricians to be available when $\stackrel{\varrho}{\simeq}$ required. They would work under the general 
direction of the specialist obstetrician and in the same building. The specialist staff of the hospital would benefit from the close contact with family doctors, who have had continuous care of their patients for lengthy periods of time, and the patient would also benefit by having more continuity of care by one doctor. High-risk cases would continue to be the responsibility of the specialist obstetrician. However the management of 'normal' labour is usually the responsibility of the midwife, and in large maternity units in urban areas she is supported by the obstetric and paediatric team which is immediately available. In these circumstances the family doctor may feel that whatever his responsibilities in the antenatal and postnatal periods the management of labour should be left to the specialist staff of the hospital.

The future of general practice is much debated. Increasing importance is now attached to preventive medicine, early diagnosis, and the social, emotional, and hereditary factors of disease. While the value of the personal doctor is generally acknowledged, the development of health centres, in which a number of doctors work suggests that the future lies in individual doctors having a special interest and postgraduate training in a particular aspect of medicine in addition to their work as a family doctor. This would widen the general practitioner's responsibility for diagnosis and therapy. There would be more scope for family doctors with varying aptitudes and personal qualities to develop and make use of their skills.

The present failure to prevent unwanted pregnancies despite the availability or reliable methods of contraception and the necessity of recourse to abortion is very disappointing. Clearly more needs to be done in prevention, and in this the family doctor with an active interest in the general education of the young and in health and sex education, in particular, should have a vital role to play in the future. He should have close contact with the schools, parents, and the various social agencies which may be concerned. A medical graduate starts off with the considerable advantage of contimuity of care of the patient and the family circle, and high prestige in the community. In addition his knowledge of physiology, endocrinology, and psychology should enable him to be a more effective counsellor than one who is not medically qualified. Nurses, health visitors or counsellors dealing with sex problems should work under the general guidance of a family doctor with a special interest in this field.

\section{ConClusions}

Fifty years ago the priority in obstetric practice was to lower the very high maternal mortality rate by improving the standard of obstetric care, the emphasis being on operative technique. At the 42nd Congress of the Royal Sanitary Institute in Glasgow in 1931, Professor Munro Kerr outlined his proposals for a national maternity service (Munro Kerr, 1931) which closely resembled the maternity service provided as part of the National Health service 17 years later in 1948. Those who worked with him and had the privilege of being taught by him will always remember his stimulating and warm personality and his great sympathy for the stunted and poverty-stricken mothers of the east end of Glasgow who filled the wards at 'Rottenrow'.

The national food policy which played such an important part in the fall in the perinatal mortality rate during the second world war owed much to the outstanding work on nutrition done at the Rowett Institute in Aberdeen under the leadership of its distinguished director, Lord Boyd Orr.

The changes in the human reproductive pattern to be expected in the next 50 years are much more difficult to predict than was the case in 1924. Man is no longer governed by the slow process of natural selection. He has new powers to manipulate his environment and his genetic potential, but there is doubt as to whether he is wise enough to use it constructively. It is a hopeful sign that there is increasing discussion throughout the world on over-population, depletion of the non-replaceable resources, and pollution. Dr Maurice Strong, the executive director of the United Nations Environmental Programme, has stressed that the world needs urgently an awareness by all nations of the importance of population policies designed to limit growth together with practical proposals as to how they can achieve this.

The growing awareness of the people of Britain of the urgent need to reduce their numbers and to be more conservative in the use of the world's resources will very soon lead them to reduce the birth rate still further below replacement level. An official lead by the British Government along these lines is urgently required.

Requests for reprints: Sir Dugald Baird, Medical Sociology Research Unit, Westburn Road, Aberdeen ABG 2ZB.

\section{REFERENCES}

BAIRD, D. (1969). An area maternity service. Lancet, 1, 515.

- (1974a). The epidemiology of low birth weight: changes in incidence in Aberdeen 1948-72. J. biosoc. Sci., 6, 323. 
(1974b). Epidemiology of congenital malformations of the central nervous system in (a) Aberdeen and (b) Scotland. J. biosoc. Sci., 6, 113.

(1975). The changing pattern of human reproduction in Scotland 1928-72. J. biosoc. Sci., 7, 77.

and Thomson, A. M. (1969). Second Report of the 1958 British Perinatal Mortality Survey. Livingstone, Edinburgh and London.

CIBA Foundation Symposium (1974). Size at Birth, 27.

Dunlop, J. C. H. (1971). Perinatal mortality experience in cases of pre-eclampsia (1957-71). Medical and Clinical Report, Simpson Memorial Maternity Pavilion, Edinburgh, p. 25.
IllsLey, R. (1963). Social Correlations of Perinatal $\mathcal{D}$ Mortality: First Report on the 1958 British Perinatal Mortality Survey. Livingstone, Edinburgh and London. and GILL, D. (1968). New fashions in illegitimacy. New Soc., 14 November, 709.

MUNRo KerR, J. M. (1931). A national maternity service. J. roy. sanit. Inst., 3, 4.

Scottish Home and Health Department (1974). Report on an Enquiry into Maternal Deaths in Scotland (1965-71). HMSO, Edinburgh.

Transactions of the XIIth British Congress of Obstetrics and Gynaecology (1949). Austrial Press, London. 